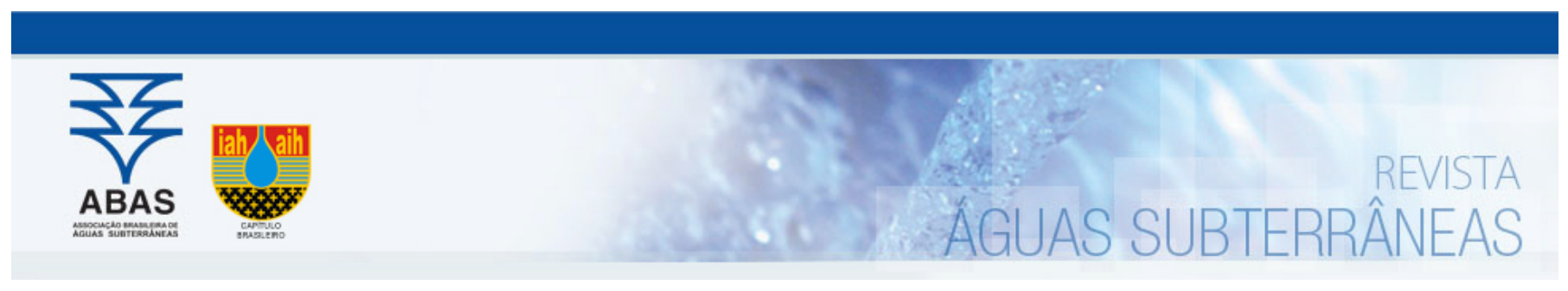

Artigos

\title{
Análise das relações entre resistividade elétrica, condutividade hidráulica e parâmetros físico-químicos para o Aquífero Livre da Região de Corumbataí (SP)
}

\section{Analysis of the relationship between electrical resistivity, hydraulic conductivity and physico-chemical parameters for the Aquifer Free of the Corumbataí (SP)}

\author{
Fernanda Teles Rosa ${ }^{1}$; Cesar Augusto Moreira ${ }^{1}$; Alan Carrara ${ }^{1}$; Shaiely Fernandes dos Santos ${ }^{1} \bowtie$ \\ 1 Universidade Estadual Paulista (UNESP), Campus de Rio Claro, SP, Brasil.
}

$\triangle$ fernandatgr1@gmail.com, moreirac@rc.unesp.br, alancarrara05@gmail.com, fer.shay@gmail.com

\begin{tabular}{ll} 
& Resumo \\
\cline { 2 - 3 } & O Brasil é um país privilegiado em relação aos seus recursos naturais, mas enfrenta problemas de diagnóstico da situação das \\
Palavras-chave: & águas superficiais e subterrâneas, devido à qualidade e a quantidade deste recurso. Questões quanto aos parâmetros físico- \\
Aquiclude. & químicos como elevada salinidade ou baixa condutividade hidráulica podem prejudicar o uso deste recurso hídrico subterrâneo. \\
Salinidade. & O estudo de procedimentos para diagnóstico direto e indireto de salinidade em aquíferos pode auxiliar na seleção de locais \\
Tomografia elétrica. & adequados para que ocorra a captação da água. Neste sentido, este estudo descreve uma análise comparativa entre dados \\
Permeabilidade. & geoquímicos e ensaios geofísicos em um aquífero livre, com salinidade elevada, numa tentativa de estabelecimento de corre- \\
& lações entre dados diretos e indiretos, além de possibilitar uma análise das limitações de uso do método geofísico da eletrorre- \\
& sistividade como ferramenta indicadora de graus de salinidade. O contexto geológico local é representado por solos argilosos \\
& assentados sobre siltitos e argilitos da Formação Corumbataí, unidade geológica pertencente à Bacia Sedimentar do Paraná. \\
& Esta unidade representa um aquiclude regional, com o nível aquífero livre no contato solo/rocha, caracterizado por salinidade \\
Keywords: & variável e bastante utilizado como fonte de abastecimento em propriedades rurais. Os parâmetros físico-químicos medidos em \\
Aquiclude. & amostras coletadas em poços foram: sólidos totais dissolvidos (STD), condutividade elétrica (CE), além de medidas de conduti- \\
Salinity. & vidade hidráulica (k). Os dados de STD e CE foram amplamente variáveis, mas resultaram numa correlação direta satisfatória. \\
Eectrical resistivity tomography. & A comparação entre dados de resistividade elétrica com STD e com k não resultaram em correlações com resposta tão satisfa- \\
Permeability. & tória, devido à complexidade geológica e salinidade amplamente variável, fatores que controlam a resistividade elétrica no
\end{tabular}

Abstract

\begin{abstract}
Brazil is a privileged country in relation to their mineral resources, but have problems in diagnosis the situation about the surface water and groundwater, because the quality and the quantity of water. Questions about physico-chemical parameters as high as salinity or low hydraulic conductivity can affect the use of this underground water resource. The study of procedures for diagnostic directly or indirectly in salinity in groundwater can assist the selection of sites for acquisition. In this direction, this study describes a comparative analysis between geochemical analyzes and tests on geophysical study of saline free aquifer, in an attempt to establish correlations between data, whether direct or indirect, in addition to providing an analysis of the limitations of the DC Resistivity geophysical method as indicator tool of degrees of salinity in an indirect way. The geological site consist in clay soils settled on siltstone and argillites of the Corumbataí Formation, of the Basin of Paraná Sedimentary Basin in Brazil. This unit represents an aquiclude regional, the occurrence of level free aquifer in the contact soil/rock characterized by variable salinity and is widely used as a source of supply for rural properties. The physical-chemical parameters measured in samples collected in wells were: total dissolved solids (TDS), electrical conductivity (CE), in addition to measures of hydraulic conductivity (k). The data of TDS and CE were widely variable, but resulted in a direct correlation. The comparison between the data from electrical resistivity with TDS and electrical resistivity with hydraulic conductivity do not result in satisfactory correlations perchance the complexity geological and a high variable in salinity. Factors that control electrical resistivity in the geological environment.
\end{abstract}

DOI: http://dx.doi.org/10.14295/ras.v31i4.28878 


\section{INTRODUÇÃO}

A água é fundamental para a saúde humana e essencial para o funcionamento biológico, desde o metabolismo dos organismos vivos até o equilíbrio dos ecossistemas. 0 aumento acelerado por demanda deste recurso ocasiona problemas de escassez, ao mesmo tempo em que a ausência de saneamento básico resulta na queda da qualidade das águas. Uma alternativa para a escassez do recurso superficial é a captação em aquíferos, principalmente em regiões distantes dos grandes centros ou de redes de abastecimentos, caso das propriedades rurais (BICUDO et al., 2010).

Com isso, a extração às vezes de forma inadequada ou desenfreada pode gerar problemas com a qualidade das águas subterrâneas que serão utilizadas pela população. A qualidade e a disponibilidade das águas subterrâneas é um fator determinante para o uso e ocupação tanto em áreas urbanas quanto áreas rurais.

As consequências da exploração desenfreada são visíveis principalmente na redução da capacidade produtiva do poço e consequentemente aumento no custo para o bombeamento. Podem ocorrer também problemas como a indução de fluxos laterais de água salina em locais de costa marinha, a subsidência do terreno devido a problemas de instabilidade e a presença de altos valores de salinidade em determinados aquíferos, que podem impactar negativamente as atividades em zonas agrícolas que envolvam irrigação, resultando em uma concentração de sais na zona radicular, quando estes não são lixiviados após a evaporação ou a absorção da água pelas plantas (HISCOCK, 2005). Neste sentido, são recomendados estudos prévios para uma correta gestão dos aquíferos.

Os métodos geofísicos em hidrogeologia são comumente utilizados quando é necessário adquirir maiores informações do meio geológico, tais como o nível freático, espessura da camada aquífera ou sentido de fluxo, entre outras informações. Estudos de correlação entre parâmetros geofísicos e hidrogeológicos podem proporcionar análises com amplo grau de detalhamento amostral, além de possibilitar integrações entre camadas saturadas e insaturadas. Condicionantes hidrogeológicos como porosidade, conectividade entre poros, salinidade, fraturamento, grau de saturação, dentre outros, são fatores que controlam a variação de parâmetros físicos como a resistividade elétrica (RUBIN \& HUBBARD, 2005; KNODEL et al., 2007).

Diversos trabalhos demonstram a possibilidade de análises de parâmetros hidrogeológicos e físico-químicos a partir de dados indiretos, obtidos principalmente por meio de estudos geofísicos. No trabalho de Kelly \& Frohlich (1985) é apresentada uma correlação positiva entre os dados geofísicos e os parâmetros hidrogeológicos, mas é principalmente ressaltado que a correlação direta não deve ser esperada no caso de aquífero livre que contém materiais argilosos. Já no trabalho de Moreira et al. (2013), o método da Eletrorresistividade permitiu a determinação da profundidade do nível freático e estimou a espessura de horizontes aquíferos, com o objetivo de correlacionar os parâmetros de resistividade e cargabilidade com as medidas diretas de condutividade hidráulica em poços rasos para determinação de relações estatísticas entre parâmetros geológicos, com resultados satisfatórios de correlação. No trabalho de Chandra et al. (2008) é feita uma analogia que parte do princípio da Lei de Darcy e a Lei de Ohm para uma estimativa partindo do parâmetro de resistividade obtido por meio da técnica de sondagem elétrica vertical (SEV) para gerar mapas de condutividade hidráulica e transmissividade, no ambiente de rochas graníticas na região de Maheshwaram na Índia. Os resultados são apresentados através de um gráfico, e o valor de correlação é considerado satisfatório pelos autores.

Devido a resultados satisfatórios destas correlações, para este estudo foram realizadas aquisições de dados geofísicos através do método eletrorresistivo e efetuadas medidas físico-químicas da água provenientes de poços rasos com captação em aquífero livre nos municípios de Corumbataí e Rio Claro (SP). Esta região é reconhecida pela elevada salinidade natural das águas em nascentes e poços rasos, atribuída à liberação de sais contidos em siltitos e argilitos sedimentados em ambiente marinho raso (SOUZA, 1985).

\section{2. ÁREA DE ESTUDOS}

A região está situada nos municípios de Corumbataí e Rio Claro, no estado de São Paulo, a cerca de 180 Km de distância da capital paulista. Está localizada na depressão periférica entre as margens pré-cambrianas do planalto cristalino e as escarpas das zonas de cuestas dos derrames basálticos do planalto ocidental paulista (CEAPLA, 2016). Os aspectos climáticos da região são bem definidos e apresentam características subtropicais com duas estações bem definidas, seca no inverno e úmido no verão.

A área de estudos pertence da Bacia hidrográfica do Piracicaba, Capivari e Jundiaí, na sub-bacia do Rio Corumbataí. É abastecida pelo rio Corumbataí com a nascente na região da região da Serra de Santana a $800 m$ e a sua foz no rio Piracicaba (SSRH, 2013) (Figura 1). 


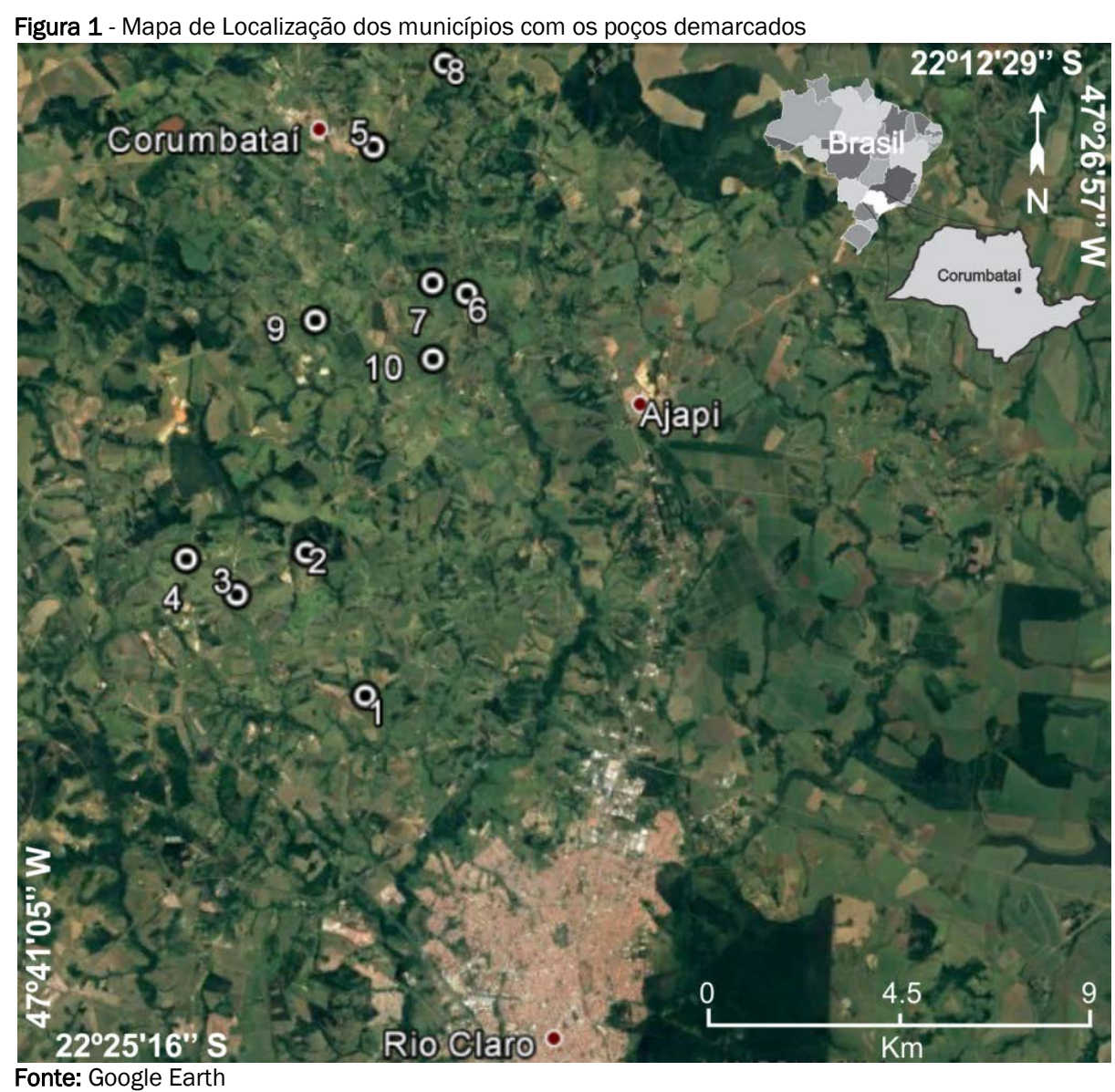

A região do levantamento é coberta pela geologia da Formação Corumbataí, unidade que compõe o Grupo Passa Dois, localizada a nordeste da Bacia sedimentar do Paraná. É caracterizada por apresentar intercalações entre siltitos, argilitos, arenitos e folhelhos, pacotes com cores arroxeadas à avermelhadas, com intercalações de bancos carbonáticos, silexíticos e camadas de arenitos finos de idade do perminano superior. A Formação Corumbataí é formada por sedimentos depositados em ambiente marinho, a cerca de 250 e 230 milhões de anos (PERINOTTO et al., 2008).

A região de estudos está sob condições hidrogeológicas de um aquiclude, devido sua baixa capacidade em fornecer água, denominado Passa Dois. Algumas vezes, é classificado localmente como aqüitarde, pois pode apresentar, eventualmente, fraturas na rocha com certa produtividade de água. Esta unidade geológica sedimentar separa os aquíferos Tubarão e Guarani, e aflora em uma faixa estreita de norte ao sul do Estado de São Paulo, passa pelas cidades de Porto Ferreira, Pirassununga, Rio Claro, Cesário Lange, Angatuba, Paranapanema e Fartura. Sua capacidade em fornecer água é baixa devido aos sedimentos finos que definem esta unidade hidroestratigráfica como uma camada confinante que não tem capacidade suficiente em transmitir água. Apresenta valores baixos de condutividade hidráulica, mesmo que em determinados pontos os valores de porosidade sejam elevados. Devido à produtividade bastante baixa, esta unidade é pouco explorada (IG; CETESB; DAEE, 1997).

Em poços cadastrados no SIAGAS plataforma da CPRM os dados apresentados de vazão são baixos, com valores desde 1,5 m³ $/ \mathrm{h}$ em poço com 100 metros de profundidade delimitado por solo até os 36 metros e em profundidade maior o argilito associado ao siltito. Valor de $1,8 \mathrm{~m}^{3} / \mathrm{h}$ em poço com profundidade de 101 metros e o maior valor de vazão para poços perfurados somente na Formação Corumbataí de $8 \mathrm{~m}^{3} / \mathrm{h}$ em poço a 60 metros de profundidade sob o arenito de fino a grosso e o siltito.

Verificações de campo permitiram constatar que em todos os pontos analisados, os solos são resultados diretos do intemperismo de siltitos e argilitos da Formação Corumbataí e, portanto, autóctones. A exploração de água das propriedades rurais desta região é realizada por meio de poços rasos em uma unidade de aquífero livre com características de baixa condutividade hidráulica e elevado teor de argila. O solo de cobertura da Formação Corumbataí nos casos de acumulação de água superficial absorve a água da recarga (água das chuvas) e atua como agente regulador do fluxo subterrâneo que alimenta dos pontos de descarga (SILVA \& KIANG, 2017).

\section{MATERIAIS E MÉTODOS}

Em campo, a princípio foi realizado o reconhecimento da área em busca de propriedades rurais que continham poços com escavação manual, em seguida se iniciaram a coletada de dados referentes à localização do poço, profundidade do poço do nível estático e também a estimativa do tempo de recarga do poço. Esta etapa consistiu no rebaixamento do poço através de bomba quando existente ou na ausência, os dados foram obtidos a partir de ensaios de permeabilidade dos solos, através de um ensaio pontual de bombeamento. Esse procedimento tem como resposta as medidas de condutividade hidráulica gerada a partir de medidas do tempo de recarga do poço e o volume medido no tempo, referentes a um único ponto (ABGE, 1996). 
Com o poço reabastecido foram realizadas as medidas geoquímicas da água por meio de medidor portátil modelo $\mathrm{pH}-1500$, fabricado pela Instrutherm (Brasil) (INSTRUTHERM, 2017) programado para quantificação de parâmetros como sólidos totais dissolvidos (STD) e medidas de condutividade elétrica (CE). Os valores dos dados foram classificados em altos e baixos, devido á realização de uma média simples, entre os maiores e menores valores obtidos.

O método geofísico aplicado foi da Eletrorresistividade, por meio da técnica de tomografia elétrica da qual forneceu respostas dos valores de resistividade representados em modelos de inversão e em cada um deles foi adicionado à profundidade do nível freático medido. As linhas de aquisição preferencialmente tinham o poço de captação de água centralizado e foram posicionadas paralelas ao sentido de fluxo da água.

Definido por parâmetros físicos de resistividade e/ou condutividade o método eletrorresistivo parte fundamentalmente do uso do campo elétrico terrestre ou de campos gerados a partir de correntes artificiais injetadas no solo, e sua resposta é obtida através da diferença de potencial gerada entre os meios geológicos (KIRSCH, 2009). A expressão que rege este comportamento consiste na injeção de corrente (I) no solo por intermédio de um par de eletrodos denominados $\mathrm{A}$ e $\mathrm{B}$, e a medida da diferença de potencial $(\Delta V)$ é resultante da passagem desta corrente através de outro par de eletrodos situados nas proximidades denominados
M e N e K é o fator geométrico definido pela disposição dos eletrodos em determinado arranjo de campo.

$$
\rho=\mathrm{K} \frac{\Delta V}{I}
$$

0 arranjo de aquisição de dados foi o dipolo-dipolo com comprimentos distintos e abertura dos dipolos de 1 metro a 4 metros, fator determinado a partir da profundidade do nível freático ( $\mathrm{Fi}$ gura 2). Neste arranjo, os eletrodos de corrente e de potencial são caracterizados por uma separação crescente, ao longo da linha de aquisição e o espaçamento entre os dipolos de corrente e potencial permanece fixo durante todo o levantamento. A incidência da corrente elétrica é de forma inclinada, com característica de distorção lateral na propagação de campo elétrico (MUSSETT \& KHAN, 2000; KNÖDEL et al., 2007).

Os dados geofísicos foram adquiridos através do resistivímetro da ABEM Terrameter LS (Suécia), que consiste em módulo único de transmissão e recepção de sinais automatizados a partir de programação prévia. Através de cabos, o equipamento injeta a corrente no solo e faz a leitura da diferença de potencial obtida, a partir dos eletrodos distribuídos na superfície (ABEM, 2012).

O processamento dos dados tomográficos foi realizado pelo software RES2DINV (Geotomo-Malásia) que gera um modelo bidimensional a partir dos dados de entrada, interpolando os conjuntos de dados (GEOTOMO, 2016).

Figura 2 - Procedimentos adotados em campo: a) poço de captação de água e leitura da profundidade do poço; b) medidas dos parametros fisicoquímicos; c) resistivimetro; d) eletrodos

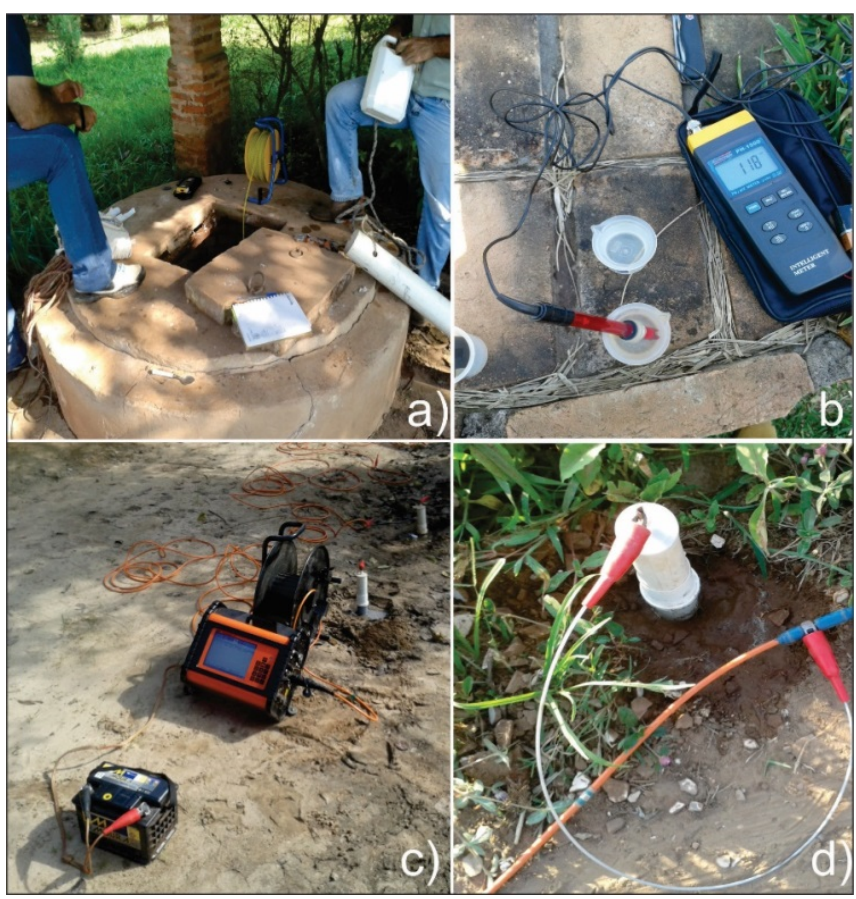

\section{RESULTADOS E DISCUSSÕES}

O padrão característico dos modelos de inversão apresentados é a diminuição do valor de resistividade com o aumento da profundidade.

Os valores elevados de resistividade desde $93 \Omega . m$ até aproxi- madamente 300 S.m são relacionados aos niveis mais rasos e indicam o predomínio de solo seco mais resistivo com espessura de camada variável em cada uma das linhas. Com o aumento da profundidade, o horizonte aquífero é definido por valores entre 8 $\Omega . m$ a $50 \Omega$.m. E o nível freático medido nos poços é variável em cada seção, desde $0,7 \mathrm{~m}$ no poço da linha 3 , até a maior profundidade de $13,07 \mathrm{~m}$ no poço referente a linha 9 (Figuras 3 e 4 ). 
O produto das análises fisico-químicas permitiu, o estabelecimento da correlação entre os parâmetros de CE e STD, atribuída prinicipalmente a facilidade de trânsito de corrente elétrica em soluções mais salinas.

Figura 3 - Modelos de inversão de resistividade elétrica

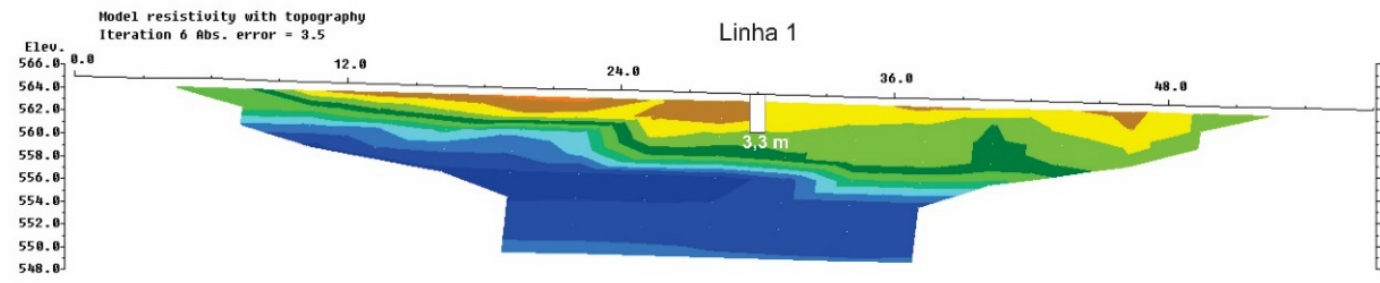

Linha 2
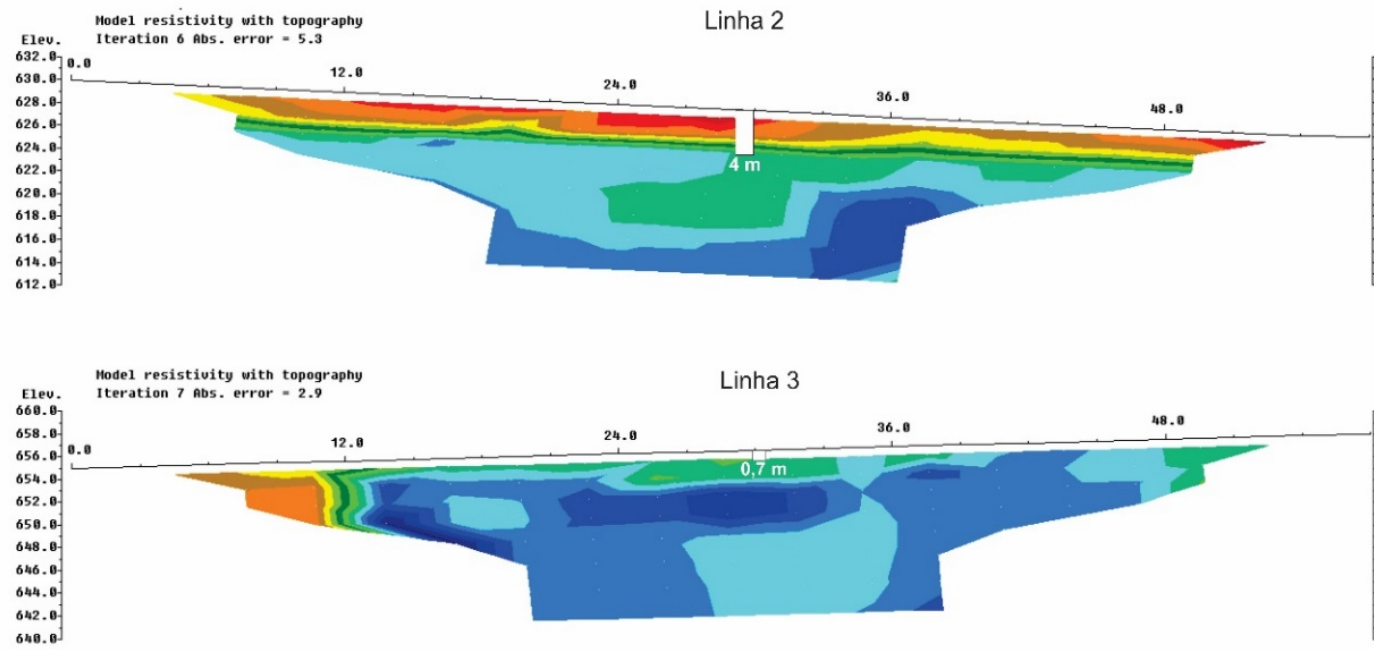

64.8.

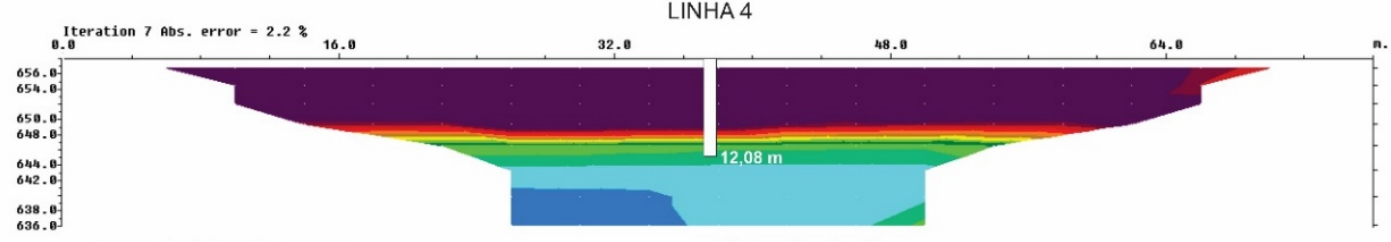

638.0.9.

Model resistivity with topography

Linha 5
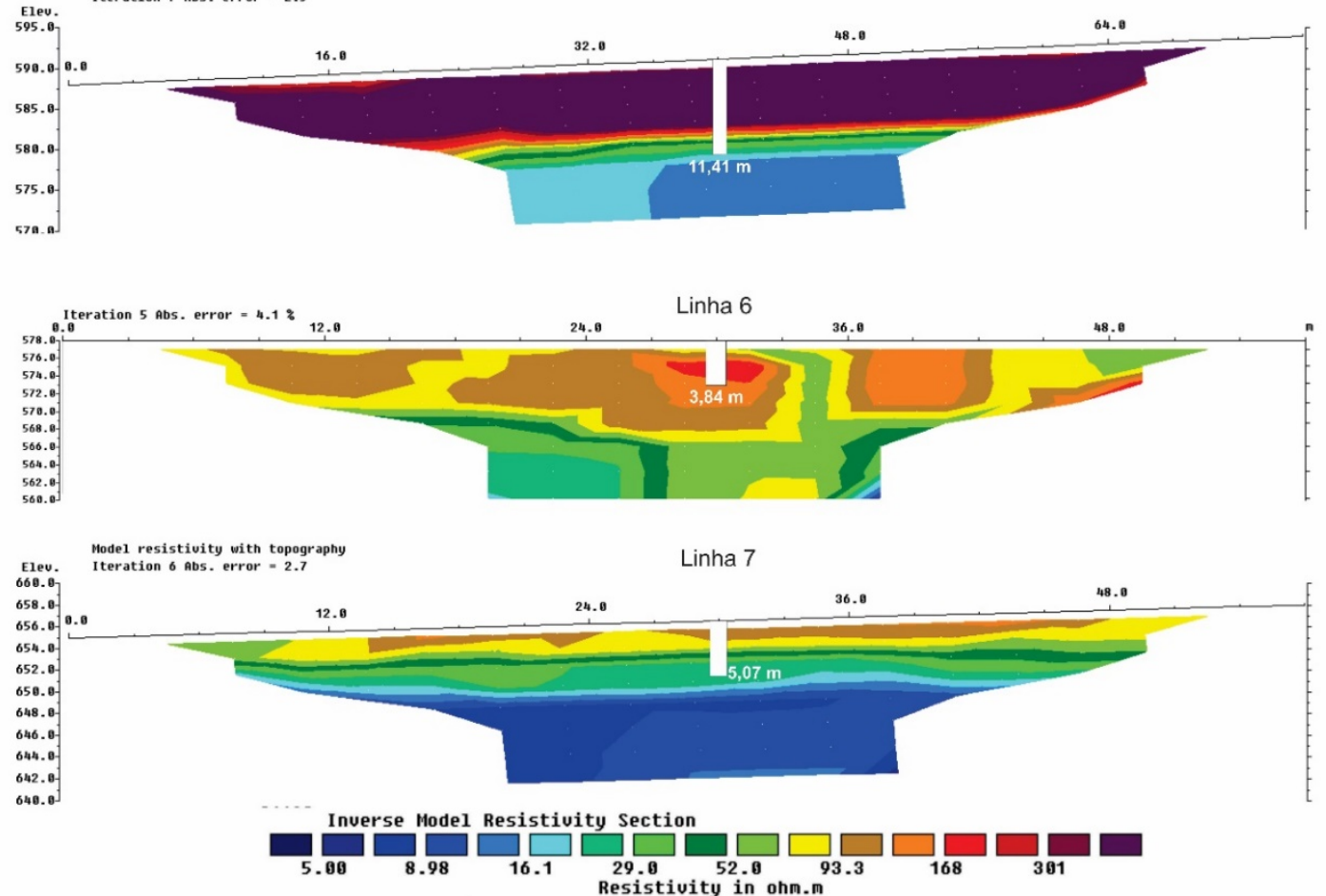
Figura 4- Modelos de inversão de resistividade elétrica

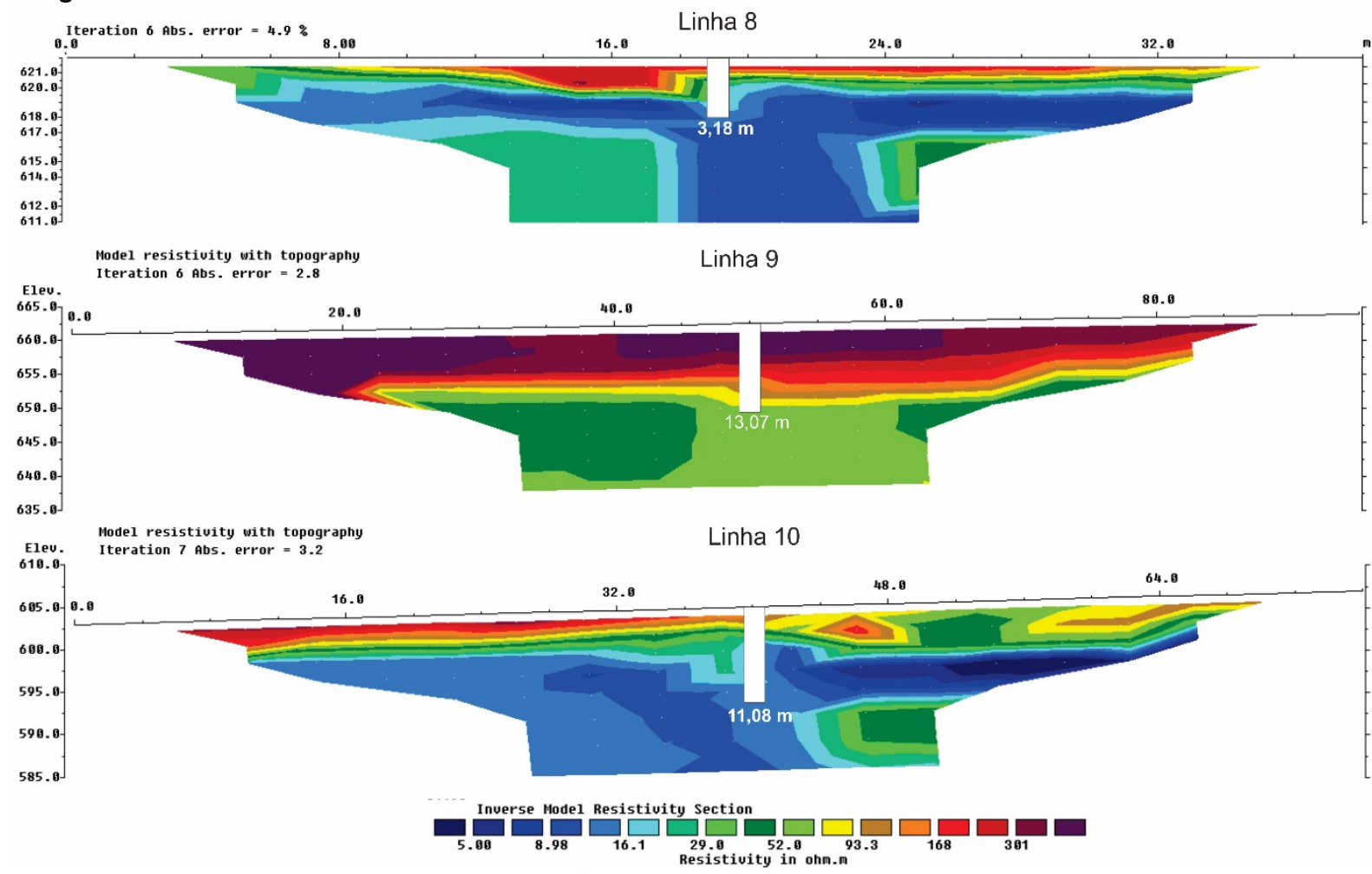

Tabela 1 - Dados dos parametros físico-quimicos

\begin{tabular}{cccccc}
\hline Linhas & $\begin{array}{c}\text { S TD } \\
(\mathbf{p p m})\end{array}$ & $\begin{array}{c}\mathbf{C E} \\
\mathbf{( m ~} \mathbf{S})\end{array}$ & $\begin{array}{c}\mathbf{K} \\
\left(\mathbf{m}^{\mathbf{3}} \mathbf{h} \mathbf{)}\right.\end{array}$ & $\begin{array}{c}\text { Resistividade } \\
\text { (ohm.m })\end{array}$ & $\begin{array}{c}\text { Nivel freático } \\
\mathbf{( m )}\end{array}$ \\
\hline 1 & 320 & 0,48 & 0,058 & 82 & 3,3 \\
2 & 90 & 0,134 & 0,176 & 23 & 4 \\
3 & 345 & 0,337 & 0,056 & 29 & 0,7 \\
4 & 224 & 0,535 & 0,052 & 19 & 12,08 \\
5 & 23 & 0,036 & 0,072 & 29 & 11,41 \\
6 & 54 & 0,064 & 0,098 & 148 & 3,84 \\
7 & 244 & 0,363 & 0,104 & 27 & 5,07 \\
8 & 279 & 0,413 & 0,187 & 12 & 3,18 \\
9 & 169 & 0,254 & 0,164 & 63 & 13,07 \\
10 & 218 & 0,055 & 0,07 & 14 & 11,08 \\
\hline
\end{tabular}

Figura 5 - Correlação entre a condutividade elétrica versus STD a) 10 pontos b) 7 pontos
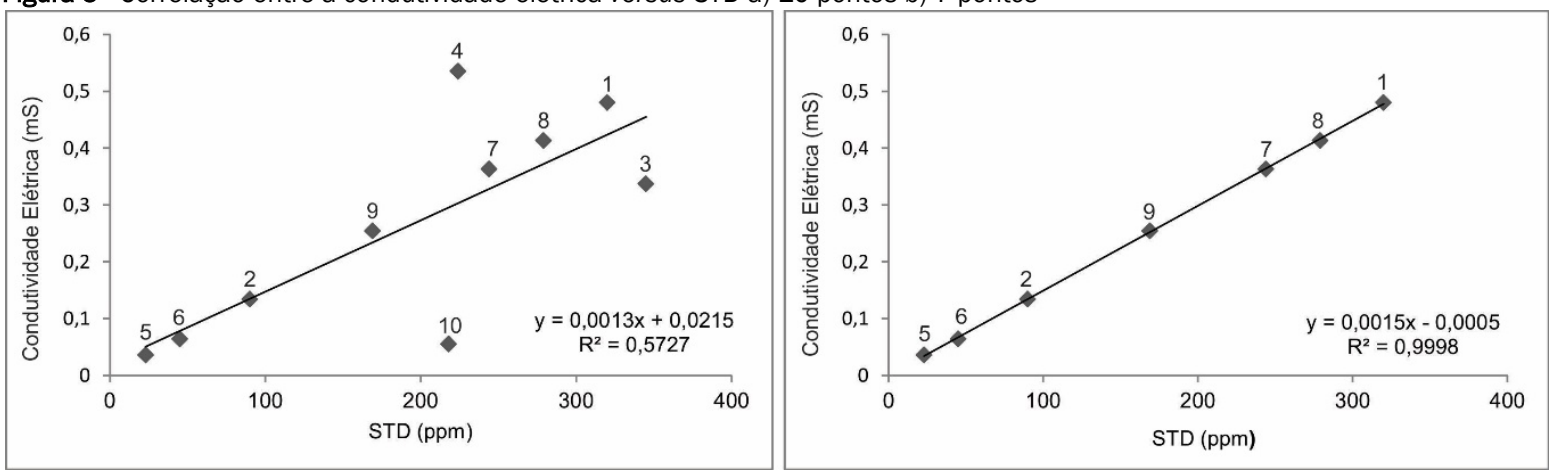
No gráfico (Figura 5a), é possível notar que o valor de $\mathrm{R}^{2}=$ 0,5727 é baixo, embora com correlação Pearson adequada para o número de pontos. No gráfico posterior (figura 5b) é possível observar que na ausência destes poços, o valor da correlação entre o restante dos dados é alto de $\mathrm{R}^{2}=0,9998$.

Os pontos referentes às linhas 3,4 e 10 são os únicos distantes do ajuste da linha de tendência o que influência o coeficiente de correlação de forma negativa. Os modelos de inversão das linhas 3 e 4, apresentam comportamento semelhante em relação aos dados geoquímicos medidos. Os valores de CE e STD são altos, e baixos os valores de condutividade hidráulica $(k)$ e resistividade. 0 nível freático para as linhas 3 e 4, está a 0,7 metros e 12,08 metros de profundidade respectivamente. Na linha 10, a propagação da corrente elétrica do arranjo aplicado, é capaz de definir estruturas verticais, sugerindo que exista uma fratura nesta linha, devido à forma da resposta da propagação de campo elé- trico obtido e a alteração dos valores de resistividade. Os parâmetros físico-químicos são variáveis, o STD medido é alto, e os dados de resistividade, CE e $\mathrm{k}$ são baixos. $O$ nível freático é mais profundo em relação às medidas obtidas em outras linhas, de 11,08 metros.

Contudo, estes poços apresentam heterogeneidades principalmente devido à geologia local, que alteram os parâmetros hidrogeológicos, como excesso de faturamento visíveis, variações faciológicas e níveis silicificados analisados em afloramentos. Problemas manuais como coleta de amostra de água com argila, para definição dos parâmetros geoquímicos, poderia afetar os resultados dos dados.

Será apresentada a correlação dos resultados obtidos referentes aos dados de STD, k e medidas do nível freático (Figura 6).

Figura 6 - Condutividade hidráulica versus STD e Nível freático versus STD

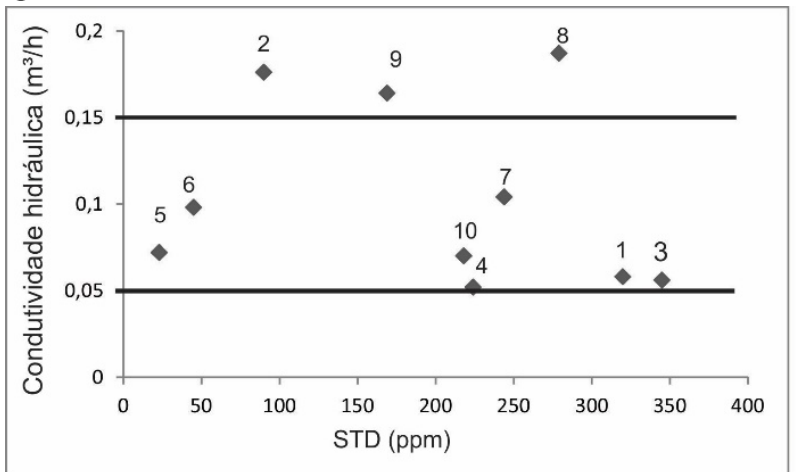

Nas duas faixas de valores definidos, os dados de $k$ e STD variam consideravelmente, um exemplo é entre o poço 1 e 8 , que o nível freático é semelhante entre eles, assim como os dados de STD e as medidas de $\mathrm{k}$ variam consideravelmente, de $0,058 \mathrm{~m}^{3} / \mathrm{h}$ para a linha 1 á $0,187 \mathrm{~m}^{3} / \mathrm{h}$ para a linha 8 .

Nos poços (1, 3, 4, 5, 6, 7 e 10) a faixa de valores de $k$ varia entre $0,05 \mathrm{~m}^{3} / \mathrm{h}$ até $0,15 \mathrm{~m}^{3} / \mathrm{h}$ e os dados de STD variam desde 23 ppm até $345 \mathrm{ppm}$. Outra faixa de dados de $\mathrm{k}$ varia de $0,164 \mathrm{~m}^{3} / \mathrm{h}$ até $0,187 \mathrm{~m}^{3} / \mathrm{h}$, em que três poços $(2,8$ e 9$)$ apresentam variação de STD de 90 ppm a 279 ppm.

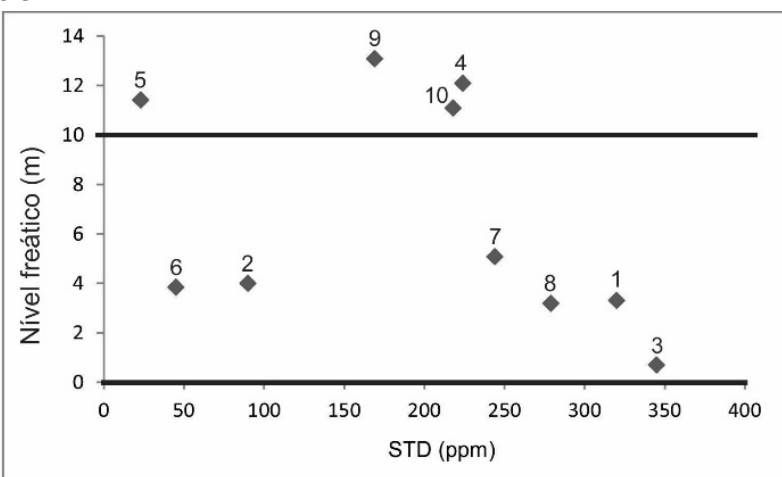

A variação dos dados de STD em relação à profundidade no nível freático também é dividida em duas faixas de valores. Os poços $(4,5,9$ e 10) a profundidade varia entre $11,08 \mathrm{~m}$ até $13,07 \mathrm{~m}$, e os dados de STD variam de $23 \mathrm{ppm}$ a $224 \mathrm{ppm}$. E os demais poços $(1,2,3,6,7,8)$ a variação da profundidade é menor, enquanto a variação de STD é ampla.

Depois de realizadas as análises referentes aos dados geoquímicos da água, os dados de resistividade e STD serão correlacionados, assim como a resistividade será correlacionada com os dados de k (Figura 7).

Figura 7 - Resistividade versus STD, Resistividade versus condutividade hidráulica

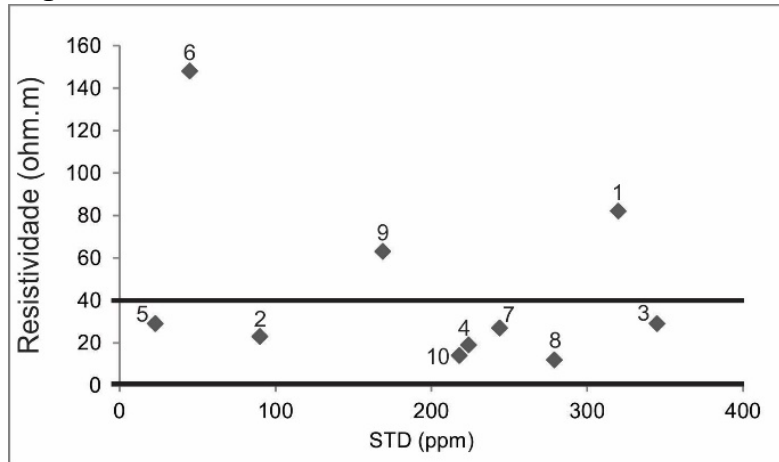

A maioria das linhas $(2,3,4,5,7,8$ e 10), está presente na faixa de valores de resistividade que varia de $10 \Omega . \mathrm{m}$ a $30 \Omega . \mathrm{m}$, os valores de $\mathrm{k}$ variam de $0,052 \mathrm{~m}^{3} / \mathrm{h}$ até $0,187 \mathrm{~m}^{3} / \mathrm{h}$. Para aos poços (1, 6 e 9) presentes na faixa de maiores valores de resistividade de 63 ohm.m até $148 \Omega$.m os dados de k variam de 0,058

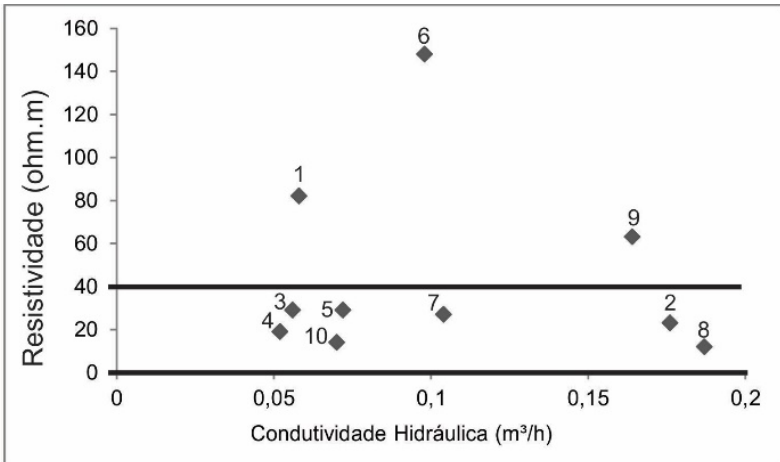

$\mathrm{m}^{3} / \mathrm{h}$ até $0,164 \mathrm{~m}^{3} / \mathrm{h}$. Em ambas as faixas de valores apresentadas, é grande a variação entre os dados.

O parâmetro físico de resistividade quando comparado ao parâmetro geoquímico de STD, também apresenta valores variáveis 
em faixas de valores definidos. Na faixa de resistividade de 10 $\Omega . m$ á $30 \Omega . m$ os dados de STD variam consideravelmente com valores que se iniciam em 23 ppm até 345 ppm.

Estas amplas variações entre os dados de resistividade em relação aos parâmetros hidrogeológicos demonstra que a relação do parâmetro físico, medido nas rochas e correlacionado com dados físico-químicos medidos na água, não apresenta uma correlação satisfatória, devido principalmente à heterogeneidade geológica.

Dos 10 poços analisados, seis deles (1, 2, 3, 4, 6 e 9) apresentam correlação direta entre os dados de CE e STD. Quando estes parâmetros são elevados, a condutividade hidráulica obtida é baixa, e o inverso, quando a condutividade hidráulica é alta os valores dos parâmetros de CE e STD são baixos.

Os dados dos poços 5, 7, 8 e 10 são variáveis entre eles quanto os parâmetros geoquímicos medidos. Os dados de condutividade elétrica, hidráulica e STD dos poços 7 e 8 são altos, no poço da linha 5 os dados físico-químicos medidos são todos baixos, e no poço 10 os dados de condutividade elétrica e hidráulica são bai- xos para um alto valor obtido para o STD. Portanto é possível notar que estes dados não obedecem a uma regra de correlação, o que gera uma discrepância entre estes dados e os demais, devido principalmente à heterogeneidade geológica restrita a estes locais de perfuração dos poços.

\section{PERFIL GEOLÓGICO - HIDROGEOLÓGICO}

Correlacionando os dados obtidos através dos modelos de inversão em conjunto com as informações de poços cadastrados pela CPRM e análises de afloramentos realizadas em campo, foi possível criar um perfil geológico hidrogeológico (Figura 8). Para criação deste, foi desconsiderada a topografia do terreno.

Na superfície está presente o solo argiloso siltoso, e quando mais seco maiores os valores de resistividade que serão obtidos. Esta camada apresenta espessura variável nos poços. Em seguida ocorre em quase todos os poços camadas de siltitos e argilitos com resistividade intermediária variável, seguido pelo nível freático.

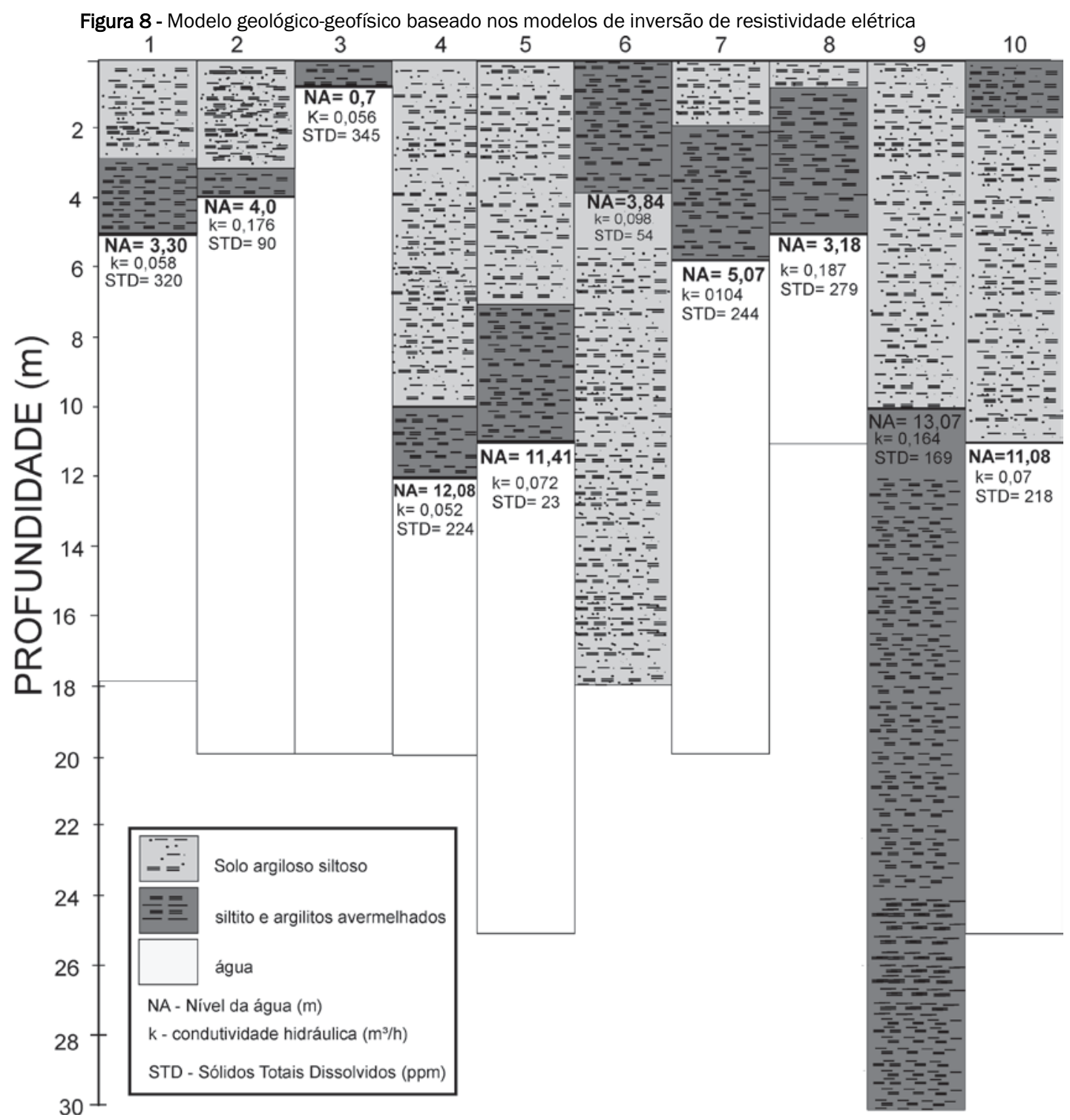




\section{CONCLUSÕES}

A Formação Corumbataí é caracterizada como um aquitarde regional entre dois importantes aquíferos e, devido a este fato, é uma unidade geológica com escassez de estudos hidrogeológicos. Embora este trabalho seja limitado a um conjunto de dados de amplitude e representatividade local, os resultados revelam que o aquífero livre definido pelo contato solo/rocha apresenta uma grande heterogeneidade em termos de salinidade e profundidade.

Fatores relacionados ao ambiente deposicional e a ação do intemperismo de forma heterogênea na área de estudos, produziram variações de espessura, estruturação e, principalmente, variações na salinidade do aquífero livre.

O cruzamento entre os dados hidrogeológicos, no caso dos parâmetros de CE versus STD resultou em correlações satisfatórias, devido à correlação entre estes parâmetros. E pode ser considerada insatisfatória quando analisados os demais gráficos gerados.

0 aquífero em estudo é altamente argiloso e com tendência de fluxo tanto em sistema poroso quanto fraturado, com baixa condutividade hidráulica e grande variações nos teores de sólidos totais dissolvidos. Tais fatores implicam num sistema de alta complexidade, em que todos os parâmetros caraterísticos exercem influência no padrão de resistividade elétrica, ou seja, o teor de sais contido no solo é tão relevante quanto o conteúdo dissolvido no aquífero. Conforme apresentado por, Kelly \& Frohlich (1985) uma correlação direta não deve ser esperada no caso de aquífero livre que contém materiais argilosos. A correlação satisfatória apresentada nos trabalhos de trabalho de Moreira et al (2013) e Chandra et al. (2008) á atribuída a um sistema aquífero relativamente homogêneo em fluxo em sistema poroso.

Desta forma, a relação entre os dados hidrogeológicos com o parâmetro de resistividade elétrica quando analisada em aquífero poroso e com quantidade significativa de argila, uma resposta de correlação satisfatória é dificultada devido à ampla variação entre os dados, e prejudica substancialmente os valores de correlação.

\section{REFERÊNCIAS}

ABEM. Instruction manual. ABEM Instrument AB. Suécia, 2012.

ABGE. Ensaios de permeabilidade em solos orientações para sua execução no campo. 3. ed. São Paulo: Associação Brasileira de Geologia de Engenharia 1996.

BICUDO, C.E. M.; TUNDISI, J.G.; SCHEUENSTUHL, M.C.B. Águas do Brasil: análises estratégicas. São Paulo, Instituto de Botânica, 2010. 204 p
CEAPLA - CENTRO DE ANÁLISE E PLANEJAMENTO AMBIENTAL. Mapa da Bacia Hidrográfica do Rio Corumbataí. Atlas Ambiental da Bacia do Rio Corumbataí, 2002. Disponível em: <http://ceapla2.rc.unesp.br/atlas/localizacao.php >. Acesso em: maio/2016

CHANDRA, S.; AHMED, S.; RAM, A.; DEWANDEL, B. Estimation of hard rock aquifers hydraulic conductivity from geoelectrical measurements: A theoretical development with field application. Jornal of Hydrology, India, p.218-227, 2008 .

DEPARTAMENTO DE ÁGUAS E ENERGIA ELÉTRICA - DAEE/SERH, INSTITUTO GEOLÓGICO - IG/SMA, INSTITUTO DE PESQUISAS TECNOLÓGICAS - IPT/SCTDE; CETESB. Mapa de água subterrâneas do Estado de São Paulo Escala 1:1.000.000, 3.v, 2005.

HISCOCK, K. M. Hydrogeology principles and practice. Blackwell Science Ltd, 2005. 405 p.

INSTRUTHERM INSTRUMENTOS DE MEDIÇÃO disponível em: <http://www.instrutemp.com.br/?esvt=-e\&esvq=instrutemp\&esvadt $=999999---1 \&$ esvcrea $=104618055044 \&$ esvplace $=\&$ esvd=c\&esvaid $=50117 \&$ gclid $=$ CNnTwqXUONECFYgHkQoddDEHSA $>$ Acesso em: $17 / 12 / 2016$

KELLY, W.E.; FROHLICH, R. K. Relation between aquifer electrical and hydraulic properties. GroundWater, v.23, p. 182-189, 1985.

KIRSCH, R. Groundwater geophysics a tool for hydrogeology. SpringerVerlag, Berlim, 2009. 556 p.

KNÖDEL, K.; LANGE, G.; VOIGT, H-J. Environmental geology handbook of field methods and case studies. Springer-Verlag, Berlim, 2007. 1374 p.

MOREIRA, C. A.; CAVALHEIRO, M. L. D.; PEREIRA, A.M.; SARDINHA, D.S. Análise das relações entre parâmetros geoelétricos e vazões para o aquí fero livre de Caçapava do Sul (RS). Associação Brasileira de Águas Subterrâneas, 2013.

MUSSETT, A. E.; KHAN, M. A. Looking Into the Earth: an introduction to geological geophysics. [S.I.]: Cambridge University Press, 2000. 493 p.

PERINOTTO, J. A. J.; ETCHEBEHERE, M. L. C.; SIMÕES, L. S. A.; ZANARDO, A. Diques clásticos na Formação Corumbataí (P) no nordeste da Bacia do Paraná, SP: análise sistemática e significações estratigráficas, sedimentológicas e tectônicas. São Paulo, Unesp, Geociências, v. 27, n. 4, p.469491, 2008.

GEOTOMO SOFT SOLUTIONS. RES2DINV - Rapid 2-D Resistivity \& IP inversion using the least-squares method, 2016.

RUBIN, Y.; HUBBARD, S. S. Hydrogeophysics. Water Science and Technology Library. Springer, Dordrecht, v. 50, 2005, p. 487-511.

SILVA, F.P; KIANG, C.H. Interferências da atividade minerária argileira nos recursos hídricos da bacia do Ribeirão Santa Gertudres/SP. Associação Brasileira de Águas subterrâneas. São Paulo, v. 1, 2017, p.78.

SOUSA, S.H.M. Fácies sedimentares das Formações Estrada Nova e Corumbataí no Estado de São Paulo. 1985. p. 142. Dissertação (Mestrado) - Instituto de Geociências, Universidade de São Paulo, São Paulo, 1985. 